\title{
Knowledge, barriers and attitudes toward dietary sodium in patients with decompensated heart failure
}

\author{
Sofia L.S. Barillii, ${ }^{1,2}$ Karina S.M. d'Almeida ${ }^{2,3}$, Melina M. Trojahn ${ }^{1,2}$, Gabriela C. Souza ${ }^{2,4}$, Graziella B. Aliti ${ }^{2,5}$, Eneida \\ R. Rabelo-Silva *1,2,3,5 \\ ${ }^{1}$ Universidade Federal do Rio Grande do Sul, Porto Alegre, Brazil \\ ${ }^{2}$ Hospital de Clínicas de Porto Alegre, Cardiology Division-Heart Failure Clinic and Transplant Group, Brazil \\ ${ }^{3}$ Cardiology and Cardiovascular Sciences, Universidade Federal do Rio Grande do Sul, Porto Alegre, Brazil \\ ${ }^{4}$ Department of Internal Medicine, School of Medicine, Universidade Federal do Rio Grande do Sul, Porto Alegre, Brazil \\ ${ }^{5}$ Nursing School, Universidade Federal do Rio Grande do Sul, Brazil
}

Received: May 7, 2017

DOI: $10.5430 /$ jnep.v8n1p98
Accepted: September 10, 2017 Online Published: September 25, 2017

URL: https://doi.org/10.5430/jnep.v8n1p98

\begin{abstract}
Background and objective: Nonadherence to sodium restriction is one of the main precipitating factors of heart failure (HF) decompensation. The three-subscale Dietary Sodium Restriction Questionnaire (DSRQ) enables evaluation of factors that can interfere with adherence. The objective of this study was to assess knowledge, barriers, and attitudes of patients with decompensated HF toward dietary sodium, by comparing those hospitalized for decompensation due to dietary nonadherence (alone or with medication nonadherence) versus those admitted for decompensation due to other causes.

Methods: Cross-sectional study carried out at the emergency departments of two public hospitals in Southern Brazil between 2013 and 2014. The sample included patients admitted for decompensated HF. Patients were divided into two groups: decompensation due to nonadherence to diet (alone or with medication nonadherence) and other causes.

Results: A total of 225 patients were included (mean age $66 \pm 12$ years). Patients exhibited a high degree of knowledge about sodium restriction (up to $50 \%$ achieved 40 of 45 points). The opinions of family and health professionals influenced adherence. The main barriers to adherence concerned palatability and dietary preferences. When compared to patients admitted for other causes, those decompensated due to nonadherence had lower ejection fraction $(p=.004)$ and higher Perceived Behavioral Control subscale scores $(p=.009)$.

Conclusions: Patients have a high level of knowledge about sodium restriction. The opinion of significant others affects adherence. Nonadherent patients appeared to be more severely ill and endorsed a greater number of barriers that prevent adequate behavior. Some factors-particularly the taste of foods and patients' dietary preferences - may justify the high prevalence of nonadherence.
\end{abstract}

Key Words: Heart failure, Sodium chloride, Dietary, Patient compliance, Questionnaires

\section{INTRODUCTION}

Heart failure (HF) has been identified as an important public health problem with high mortality and morbidity, despite advances in current therapy. Data from the American Heart Association estimate a prevalence of 5.1 million individuals with HF in the United States (2007-2012). ${ }^{[1]}$ In South

\footnotetext{
*Correspondence: Eneida R. Rabelo-Silva; Email: eneidarabelo@ gmail.com; Address: Rua São Manoel, 963 - Bairro Rio Branco, Porto Alegre, RS, Brasil - CEP 90620-110, Nursing School, Universidade Federal do Rio Grande do Sul, Porto Alegre, Brazil.
} 
America, HF is the main cause of hospitalization based on available data from approximately $50 \%$ of the population. ${ }^{[2]}$ Decompensated HF requires immediate institution of therapy and subsequent hospitalization. At hospital admission, these patients predominantly exhibit congestive manifestations, ${ }^{[3,4]}$ with hypervolemia accounting for $80.7 \%$ of hospitalizations due to decompensated HF. ${ }^{[5]}$ Almost $50 \%$ of patients hospitalized with HF are readmitted within 90 days after hospital discharge and mortality rates increase with each readmission of these patients. ${ }^{[6]}$

In view of the association between excessive sodium intake and fluid retention, restricted salt intake is the nonpharmacological self-care measure most commonly prescribed to patients with HF. ${ }^{[4,7,8]}$ Despite recurring efforts by healthcare providers to advise patients of the risks of elevated sodium intake, poor treatment adherence or nonadherence has been identified as one of the leading precipitating factors of $\mathrm{HF}$ decompensation. ${ }^{[7,9-11]}$ Data from the literature indicating that nonadherence is among the major precipitating factors of decompensation. In a US registry which identified the etiology of decompensation in more than 50,000 patients, nonadherence was the third leading cause. ${ }^{[8]}$ Furthermore, poor adherence to a low sodium diet has been associated with worse outcomes, ${ }^{[12,13]}$ including a twofold risk of hospitalization and mortality. ${ }^{[3]}$

Over the years, investigators have demonstrated that HF patients' knowledge of nonpharmacological measures alone-including a low-sodium diet - apparently does not suffice to ensure adherence to such guidance. ${ }^{[13-15]}$ Considering that other factors may interfere with adherence to sodium restriction, US researchers developed the Dietary Sodium Restriction Questionnaire (DSRQ), an instrument based on the Theory of Planned Behavior. ${ }^{[16]}$

Within this context, considering that nonadherence is a potentially preventable cause, and that high sodium intake is one of the main factors triggering HF decompensation, understanding the reasons why these patients continue to be hospitalized remains a challenge to all healthcare providers in the multidisciplinary team. In addition, the lack of studies that evaluate, besides the knowledge, questions related to resources, attitudes and barriers to follow a low sodium diet, and the possibility of targeting education and counseling interventions encouraged us to perform this study.

Thus, this investigation sought to identify the causes of decompensated HF and assess knowledge, barriers, and attitudes of these patients toward dietary sodium, by comparing those hospitalized for decompensation due to nonadherence to diet alone or to both medication and diet versus those with decompensation attributable to other causes.

\section{MeTHODS}

\subsection{Study design, sample and setting}

This was a cross-sectional study conducted at the emergency departments of two public hospitals in Southern Brazil. Data collection was carried out between October 2013 and October 2014.

A total of 225 patients were included by means of a convenience sampling strategy. The sample size was calculated on the basis of an estimated $30 \%$ prevalence of adherence to sodium restriction, ${ }^{[17]}$ with a $95 \%$ confidence interval and a $6 \%$ margin of error.

The study population comprised adult patients presenting with decompensated HF, as confirmed by a Boston Criteria score of 8 or greater, ${ }^{[18]}$ with a reduced or preserved (> 50\%) left ventricular ejection fraction (LVEF). Data regarding LVEF were obtained by echocardiography using the Teichholz or Simpson methods. ${ }^{[19]}$ Examinations performed within 6 months before inclusion in the study were considered.

Patients with cognitive disorders or any other potential barrier to understanding of the questionnaire (e.g., hearing impairment, neurological sequelae) were excluded.

\subsection{Instrument}

The DSRQ was cross-culturally adapted ${ }^{[20]}$ and validated for use in Brazilian Portuguese, with the name Questionário de Restrição de Sódio na Dieta, which demonstrated to be a reliable tool for measuring attitudes and behaviors related to adherence to dietary sodium restriction in Brazilian patients with HF. ${ }^{[21]}$ The instrument comprises 27 items. The first section consists of 11 descriptive, multiple-choice items. The second section is divided into three subscales, each of which is scored on a five-point Likert-type scale, as follows:

(1) Attitude and Subjective Norm - comprises nine items ( 9 to 45 points) that assess patient belief regarding the results of a low-sodium diet and the importance of significant others' approval or disapproval of their behavior;

(2) Perceived Behavioral Control - comprises four items (4 to 20 points) that assess patient ability to identify facilitators and barriers to adherence to a low-sodium diet;

(3) Dependent Behavioral Control - comprises three items (3 to 15 points) that assess the presence or absence of resources or hindrances to following a low-sodium $\operatorname{diet}^{[21]}$

During the process of cultural adaptation and validation, although the items of the questionnaire showed high correlation, the distribution of items in the Portuguese version 
differs from that in the original instrument. Questions 18 to 20 , related to influence of important people in behavior, became part of the first subscale (Attitude and Subjective Norm). Items 23 to 25 , because they relate to situations of decision-making, formed a new subscale: Dependent Behavior Control. Such modifications do not alter the principles of the Theory of Planned Behavior or the purpose of the questionnaire. These changes may be the result of cultural and demographic differences between the two different populations, in which the instrument was applied. ${ }^{[21]}$

Descriptive and multiple-choice items were recorded faithfully in accordance with patients' reports. To score the subscales, patients were asked to answer on a five-point Likerttype scale. Patients were explained that, on the first subscale, the lowest score denotes "strongly disagree" and the highest denotes "strongly agree"; for the second and third subscales, the lowest score is indicative of "not at all", whereas the highest score indicates "a lot".

To date, there is no established cutoff point for the DSRQ Higher values on the first subscale are indicative of higher adherence, whereas the second and third subscales are reversescored, i.e., higher scores are indicative of poorer adherence. ${ }^{[16]}$

\subsection{Procedure}

The investigation conforms with the principles outlined in the "Declaration of Helsinki" [22] and was approved by the Research Ethics Committees of the two participating hospitals. All patients were included in the study after signing a written informed consent.

Clinical and sociodemographic data were collected and the DSRQ administered by the same investigator, during a faceto-face interview, with a mean duration of 40 minutes. Data related to causes of decompensation were collected by the principal investigator (a specialist intensive care nurse with clinical experience in evaluation of patients with HF) in both institutions through chart reviews and patient reports. Causes included infection, uncontrolled hypertension (HTN), anemia, angina/acute coronary syndrome, nonsteroidal antiinflammatory drugs (NSAID), medication nonadherence, and dietary nonadherence. Before data analysis, a second researcher - blinded to both predefined groups - validated records related to decompensation due to identified and unidentified causes.

Patients were classified as nonadherent to medication or diet when the cause of decompensation described in the medical record was nonadherence to either or when all other causes of decompensation (cited above) were excluded. If applicable, more than one cause was established.
To prevent any bias due to possible interventions performed during emergency department stay (e.g., staff orientations on non-pharmacological measures), patients were interviewed as soon as they were clinically stable enough to answer the questionnaire, and sociodemographic and clinical data were collected at the same point in time.

\subsection{Data analysis}

Normally distributed continuous variables were expressed as means and standard deviations. Asymmetrically distributed variables were expressed as medians and interquartile ranges. Categorical variables were expressed as absolute or relative frequencies.

For comparison of clinical and sociodemographic variables and DSRQ scores by cause of decompensation, patients were divided into two groups: a) nonadherence to diet alone or to both diet and medication; and b) other causes. Analysis of the two groups of causes revealed that nonadherence was predominant, as it is a preventable risk factor and the object of the present study.

Five-point Likert-type scales are used to score the DSRQ subscales. The decision was made to pool patients' answers to facilitate analysis. This strategy was used in a previous paper by the researchers who developed the original instrument, ${ }^{[16]}$ as follows: in the first subscale, scores of 1 and 2 on the Likert scale were analyzed within the category "Disagree", scores of 3 as "Neutral" and scores of 4 and 5 as "Agree"; in the second and third subscales, scores of 1 and 2 were analyzed within the category "Not At All", scores of 3 in the category "Partly (Little)", and scores of 4 and 5 in the category "A Lot".

Statistical analyses were carried out in the PASW Statistics 18.0 software environment (Chicago, IL: SPSS Inc.). For comparison of continuous variables between patients admitted for dietary nonadherence, dietary and medication nonadherence, and those admitted for other causes, Student's $t$-test or the Mann-Whitney $U$ test were used as appropriate according to the distribution of data. The chi-square test was applied to assess the association between categorical variables. The significance level was set at $(p<.05)$.

\section{RESUlts}

During the data collection period, 685 potentially eligible patients were admitted by the two study centers altogether. Of these, 225 patients across both centers met the inclusion criteria. 
Table 1. Sociodemographic and clinical characteristics of the sample

\begin{tabular}{|c|c|}
\hline Variable & $n=225$ \\
\hline \multicolumn{2}{|l|}{ Sociodemographic data } \\
\hline Age (years)* & $66 \pm 12$ \\
\hline Males $(\%)^{\dagger}$ & $121(54)$ \\
\hline Years of schooling $\ddagger$ & $5(3 ; 8)$ \\
\hline Income (US\$) $\ddagger$ & $462.6(231.3 ; 639)$ \\
\hline Cohabitating (with partner or family member) $(\%)^{\dagger}$ & $187(83.1)$ \\
\hline \multicolumn{2}{|l|}{ Clinical data } \\
\hline Left ventricular ejection fraction (\%)* & $42 \pm 16$ \\
\hline HF duration (years) $\ddagger$ & $3(1 ; 7)$ \\
\hline Prior admission due to $\mathrm{HF}^{\dagger}$ & $150(67.3)$ \\
\hline Number of prior admissions due to $\mathrm{HF} \neq$ & $1(0 ; 2.2)$ \\
\hline \multicolumn{2}{|l|}{ NYHA functional classification (\%) ${ }^{\dagger}$} \\
\hline I & $3(1.3)$ \\
\hline II & $48(21.3)$ \\
\hline III & $141(62.6)$ \\
\hline IV & $33(15.8)$ \\
\hline \multicolumn{2}{|l|}{ Medications used before admission (\%) ${ }^{\dagger}$} \\
\hline Diuretics & $189(84)$ \\
\hline Beta blockers & $155(69)$ \\
\hline Angiotensin-converting enzyme inhibitors & $138(61)$ \\
\hline Digitalis & $67(30)$ \\
\hline Nitrates & $55(24)$ \\
\hline Angiotensin II receptor antagonists & 39 (17) \\
\hline \multicolumn{2}{|c|}{$\begin{array}{l}\text { *Continuous variables expressed as mean } \pm \text { standard deviation; } \\
\text { 'categorical variables expressed as n (\%); } \\
\text { łasymmetrically distributed variables expressed as median (interquartile range). } \\
\text { HF: heart failure; } \\
\text { NYHA: New York Heart Association. }\end{array}$} \\
\hline
\end{tabular}

As shown in Table 1, mean age was $66 \pm 12$ years, and $54 \%$ of the participants were male. The predominant etiology of HF was ischemic heart disease (42\%) and most patients $(63 \%)$ were in New York Heart Association functional class III at the time of the interview. The most prevalent comorbidities were HTN (83\%) and diabetes mellitus (47.5\%). The medications most commonly used before admission were diuretics (84\%) and beta blockers (69\%).

\subsection{DSRQ Section I}

The qualitative section of the questionnaire revealed that 203 of the 225 patients $(90 \%)$ had been prescribed or advised to follow a low-sodium diet. The most prevalent guidance was to "reduce salt [intake]" and "eat little salt".

Of the 22 patients to whom a low-sodium diet was not prescribed, 15 reported attempts at following a low-sodium diet for other reasons, particularly influence from the media or from family members. The remaining patients reported no attempt at following this measure.

Regarding the frequency of adherence to a low-sodium diet, the majority of patients in both groups $-53 \%$ of those who

Published by Sciedu Press had been prescribed such a diet $(n=108)$ and $47 \%$ of those who had not $(n=7)$ - believed they followed this diet most of the time.

When asked about difficulties in following the diet, patients who had been prescribed a low-sodium diet behaved similarly to those who had not: $44.4 \%$ of those prescribed the diet and $46.7 \%$ of those not prescribed the diet found it easy to follow. Conversely, a larger number of patients in the not-prescribed group $(47 \%, \mathrm{n}=7)$ found the diet hard to follow.

\subsection{DSRQ Section II}

The responses of 225 patients (items 12 to 27) are shown in Table 2. Regarding the first subscale (Attitude and Subjective Norm), patients exhibited good knowledge related to sodium restriction and its benefits in disease management (up to $50 \%$ of patients achieved 40 of 45 points). Health professionals and family members influenced adherence positively. Analysis of results on the second subscale (Perceived Behavioral Control) demonstrated that the taste of food and patients' preferences are the main barriers related to sodium restriction. Finally, regarding the third subscale (Dependent Behavior Control), decisions made outside the home did not appear to influence adherence.

The Attitude and Subjective Norm subscale had the highest median score (40 [35.5-44]), out of a maximum score of 45, followed by Perceived Behavioral Control (10 [8-14], maximum score $=20$ ) and Dependent Behavior (5 [3-7], maximum score $=15$ ).

As shown in Figure 1, the leading causes of HF decompensation at the time of hospital admission were: infection $(n=61$, $27 \%)$; uncontrolled HTN ( $\mathrm{n}=42,19 \%)$; and a combination of nonadherence to prescribed medications and nonadherence to diet $(n=40,18 \%)$. Each patient may have had more than one cause.

As shown in Table 3, comparison of clinical and sociodemographic variables and DSRQ scores between patients admitted for decompensation due to nonadherence to prescribed medication/diet vs. those admitted for decompensation with other causes showed a significant difference in LVEF ( $p=$ $.004)$ and in Perceived Behavioral Control subscale scores ( $p$ $=.009$ ).

\section{Discussion}

This was the first non-US study to use the DSRQ (in its Brazilian Portuguese version, the QRSD) to evaluate knowledge, barriers, and attitudes regarding dietary sodium among patients with decompensated HF.

Regarding DSRQ scores, the high scores observed for the 
Attitudes and Subjective Norm subscale showed that patients recognize the importance of adhering to a low-sodium diet and are capable of identifying the signs and symptoms of excessive sodium intake, as well as the benefits of low sodium intake. However, incorporating sodium restriction into daily life remains a challenge for many patients. As shown in other studies, ${ }^{[13-15]}$ knowledge per se does not appear enough to ensure adherence; in addition to education, adherence requires other skills, both personal (motivation and willpower) and behavioral (reading food labels and making alternative meals). ${ }^{[23]}$

Table 2. Knowledge, barriers, and attitudes of patients with decompensated HF toward following a low-sodium diet

\begin{tabular}{|c|c|c|c|}
\hline Attitude and Subjective Norm subscale & Disagree & Neutral & Agree \\
\hline 12. It is important for me to follow my low-salt diet. & $07(3.1)$ & $28(12.4)$ & $190(84.4)$ \\
\hline 13. Eating a low-salt diet will keep fluid from building up in my body. & $17(7.5)$ & $33(14.7)$ & $175(77.7)$ \\
\hline 14. Eating a low-salt diet will keep my swelling down. & $20(8.9)$ & $37(16.4)$ & $168(74.7)$ \\
\hline 15. Eating a low-salt diet will help me breathe easier. & 20 (8.9) & $50(22.2)$ & 155 (68.9) \\
\hline 16. When I follow a low-salt diet, I feel better. & $15(6.7)$ & $43(19.1)$ & $167(74.3)$ \\
\hline 17. Eating a low-salt diet will keep my heart healthy. & $06(2.7)$ & $22(9.8)$ & $197(87.6)$ \\
\hline 18. My spouse or other family members think I should follow a low-salt diet. & $18(8.0)$ & $22(9.8)$ & $185(82.3)$ \\
\hline 19. Generally, I want to do what my doctor thinks I should do. & $13(5.8)$ & $28(12.4)$ & $184(81.8)$ \\
\hline 20. Generally, I want to do what my spouse or family members think I should do. & $30(13.3)$ & $41(18.2)$ & $154(68.5)$ \\
\hline Perceived Behavioral Control subscale & Not At All & Partly (Little) & A Lot \\
\hline $\begin{array}{l}\text { 21. Don't understand or know how. } \\
\text { (Don't understand: The importance of a low-salt diet. Don't know how: Eats at } \\
\text { restaurants or meals are cooked by someone else and patient cannot control amount } \\
\text { of salt...). }\end{array}$ & $120(53.3)$ & $44(19.6)$ & $61(27.1)$ \\
\hline 22. Taste of low-salt foods. & $84(37.3)$ & $60(26.7)$ & $81(36.0)$ \\
\hline 23. The foods I like to eat are not low-salt. & $86(38.2)$ & $56(24.9)$ & $83(36.9)$ \\
\hline 24. I don't have the willpower to change my diet. & $132(58.7)$ & $36(16.0)$ & $57(25.3)$ \\
\hline Dependent Behavior subscale & Not At All & Partly (Little) & A Lot \\
\hline 25. Can’t pick out low-salt foods in restaurants. & $179(79.6)$ & $22(9.8)$ & $24(10.7)$ \\
\hline 26. The restaurants I like don't serve low-salt foods. & $197(79.6)$ & $15(6.7)$ & $31(13.8)$ \\
\hline 27. Can’t pick out low-salt foods at the grocery. & $155(68.9)$ & $34(15.1)$ & $36(16.0)$ \\
\hline
\end{tabular}

Note. Categorical variables expressed as n (\%). DSRQ: Dietary Sodium Restriction Questionnaire (Brazilian version).

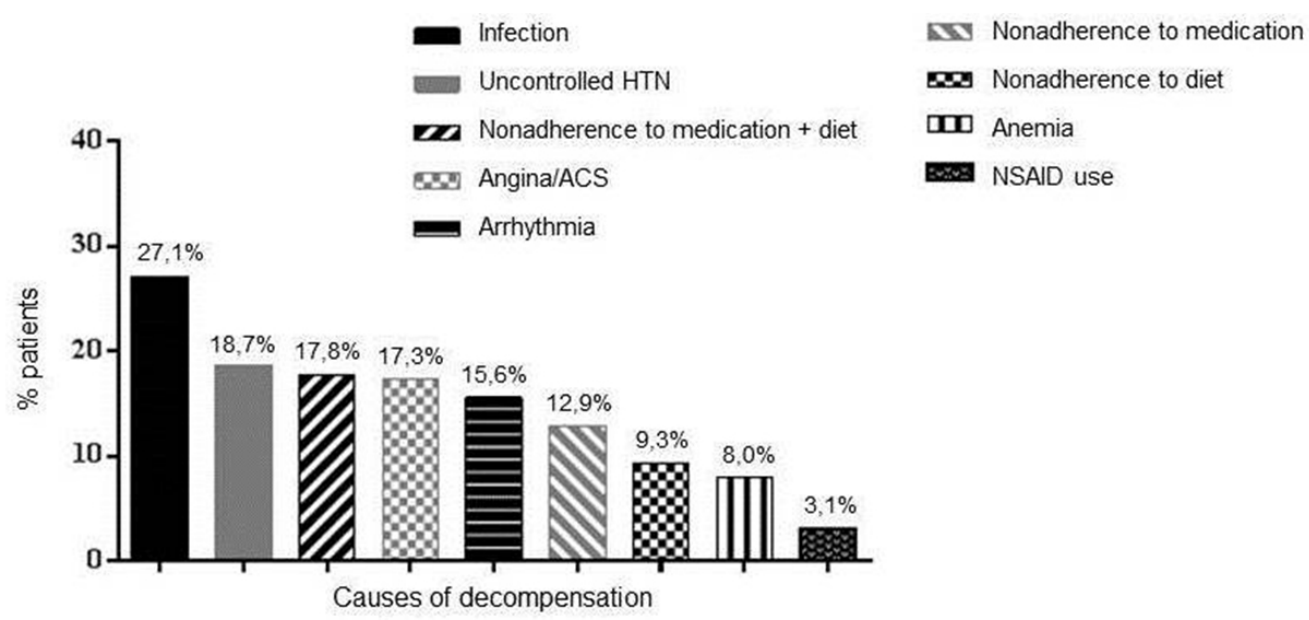

HTN: hypertension; ACS: acute coronary syndrome; NSAID: nonsteroidal anti-inflammatory drugs.

Figure 1. Causes of heart failure decompensation in the sample 
Table 3. Comparison of clinical and sociodemographic variables between patients admitted for decompensation due to nonadherence to prescribed medication/diet vs. those admitted for decompensation with other causes

\begin{tabular}{|c|c|c|c|}
\hline Variable & $\begin{array}{l}\text { Nonadherence to prescribed diet }+ \\
\text { nonadherence to medications and diet } \\
\mathbf{n}=59(26.2)\end{array}$ & $\begin{array}{l}\text { Other causes } \\
n=166(73.8)\end{array}$ & $p$ \\
\hline \multicolumn{4}{|l|}{ Sociodemographic data } \\
\hline Age (years)* & $64.2 \pm 12.5$ & $67.1 \pm 12.2$ & .113 \\
\hline Males $(\%)^{\dagger}$ & $36(61.0)$ & $85(51.2)$ & .252 \\
\hline Cohabitating (with partner or family member) (\%) ${ }^{\dagger}$ & $48(81.3)$ & 139 (83.7) & .828 \\
\hline Years of schooling $\ddagger$ & $5(4 ; 8)$ & $5(2 ; 8)$ & .174 \\
\hline Income (US\$) $\ddagger$ & $503.5(251.7 ; 679.7)$ & $427.9(251.7 ; 679.7)$ & .527 \\
\hline \multicolumn{4}{|l|}{ Clinical data } \\
\hline Left ventricular ejection fraction (\%)* & $36.8 \pm 15.3$ & $43.7 \pm 15.8$ & .004 \\
\hline Duration of HF $\ddagger$ & $3(1 ; 7.2)$ & $3(1 ; 7)$ & 900 \\
\hline Prior admission due to $\mathrm{HF}^{\dagger}$ & $40(67.8)$ & $110(67.1)$ & 1.000 \\
\hline Number of prior admissions due to $\mathrm{HF} \ddagger$ & $1(0 ; 4)$ & $1(0 ; 2)$ & 131 \\
\hline NYHA functional classification (\%) ${ }^{\dagger}$ & & & .464 \\
\hline I & $1(1.7)$ & $2(1.2)$ & \\
\hline II & $10(16.9)$ & $36(22.2)$ & \\
\hline III & $38(64.4)$ & $101(62.3)$ & \\
\hline IV & $10(16.9)$ & $23(14.2)$ & \\
\hline \multicolumn{4}{|l|}{ DSRQ scores $\ddagger$} \\
\hline Attitude and Subjective Norm subscale & $40(34 ; 44)$ & $39(36 ; 44)$ & .858 \\
\hline Perceived Behavioral Control subscale & $12(9 ; 16)$ & $10(8 ; 13.2)$ & .009 \\
\hline Dependent Behavior subscale & $5(3 ; 7)$ & $4(3 ; 7)$ & 205 \\
\hline
\end{tabular}

Still regarding the Attitudes and Subjective Norm subscale, high scores on the last three items suggest that adherence behavior is influenced by the opinions of significant others - spouses, family members, physicians, and other health professionals. Including family members in HF treatment - particularly regarding adherence to nonpharmacological measures - appears crucial and has been gaining ground as a self-care strategy. ${ }^{[24,25]}$ A US study that sought to assess the effect of educational sessions geared to the family members of HF patients showed a significant reduction in sodium intake among patients whose family members received the intervention. ${ }^{[23]}$ Family education is an effective strategy; however, grocery shopping, making meals, and eating together are important elements of family interaction. A lack of family support for these behaviors may make the patient feel isolated. Therefore, the optimal approach is to not only make family members aware of what constitutes an adequate diet, but also engage them so as to ensure adoption of such a diet. ${ }^{[12]}$ Patients and family members must support each other along this process, from planning grocery shopping to meal preparation. Realistic, achievable short- and longterm goals should be defined jointly. ${ }^{[12]}$ A recent US study found that patients with HF whose family members also followed a low-sodium diet were 1.6 times more likely to be adherent. ${ }^{[26]}$

Regular follow-up programs led by multidisciplinary teams have achieved good results in HF management. A landmark study conducted in Brazil, which sought to investigate the effects of an HF management program consisting of educational sessions and telephone monitoring of clinical outcomes, found a reduction in the number of Emergency Department visits and admissions, as well as improved quality of life and treatment adherence, in the intervention group. ${ }^{[27]}$

In the present study, when patients admitted for decompensation due to dietary nonadherence (alone or with medication nonadherence) were compared with those admitted for other causes, the LVEF was significantly lower in the former group, 
denoting increased disease severity and worse prognosis. ${ }^{[28]}$

Regarding DSRQ scores, a significant difference was found in the Perceived Behavioral Control subscale, which suggests that nonadherent patients exhibit more factors that prevent them from engaging in the desired behavior. The main difficulties observed concern the taste of low-salt foods and preference for other food types. It has long been known that the palatability of low-sodium foods is one of the main factors that prevent adherence. ${ }^{[29]}$ Dietary choices are also influenced by satisfaction and pleasure, which leads to a preference for certain foods over others. ${ }^{[30]}$ In addition, compared to healthy individuals, patients with HF have a strong predilection for salt-rich foods. ${ }^{[31]}$ This increased appetite for sodium occurs as a symptom of HF, mediated largely by hormones in the renin-angiotensin-aldosterone system, ${ }^{[32]}$ and is another factor responsible for poor adherence; therefore, it should be taken into account in the development of interventions.

Decision-making situations that take place outside the home - specified in the DSRQ as going to restaurants and going to the grocery store - did not appear to influence adherence significantly, given that lower values were found for the Dependent Behavioral Control subscale. This little interference of distinct meal-taking environments may be explained by the limitations imposed both by advanced age and by disease severity. Most of the time, patients take their meals at home and cook these meals themselves, aided or unaided. Furthermore, the task of going to the grocery store and selecting foods is usually assigned to a family member or caregiver, which may justify the low influence of this factor.

More than $90 \%$ of the patients included reported having received guidance about a low-sodium diet, and many reported adhering to this measure most of the time. Conversely, nonadherence to the diet - alongside nonadherence to prescribed medications - was the third leading cause of decompensation, surpassed only by infection and uncontrolled HTN. Other studies have reported similar results, ${ }^{[3,8,33]}$ which suggests that maintenance of an inadequate diet and failure to follow drug prescriptions are associated with worse outcomes and need for hospitalization - a factor that modifies the natural course of HF and worsens prognosis. ${ }^{[28]}$ According to two large US studies, including approximately 50,000 patients with HF, decompensation due to uncontrolled HTN or dietary nonadherence was associated with shorter length of hospital stay and lower risk of in-hospital mortality. At the time of admission, these patients predominantly present with clinical manifestations of congestion; initiation of a lowsodium diet, administration of diuretics, and simplification of pharmacotherapy lead to a rapid return to normovolemia and, consequently, clinical compensation. ${ }^{[3,8]}$ A randomized clinical trial conducted in Brazil showed that the hospitalization period is the optimal time to start the health education process, as patients who received educational nursing interventions during their hospital stays exhibited improvement both in knowledge of disease and in self-care measures, including adherence to a low-sodium diet and to prescribed medications. ${ }^{[34]}$

Although discussions are currently underway as to the role that a more sodium-permissive diet might play in disease management, it is well known that many patients with HF consume daily amounts of sodium well in excess of any recommendation. ${ }^{[28]}$ This means that difficulty adhering to treatment - including nonpharmacological measures - is one of the main hindrances in the search for better outcomes. Regardless of the cause of decompensation, unplanned admissions are always associated with poorer patient outcomes, as they signal a change in the natural course of HF progression. ${ }^{[28]}$ Therefore, hospitalizations due to preventable causes - such as treatment nonadherence - lead to worse prognoses, and multidisciplinary teams should be aware of this to enable implementation of follow-up measures during admission, telephone follow-up, ${ }^{[34]}$ and other strategies, such as a house call shortly after hospital discharge. ${ }^{[35,36]}$

A limitation of the study was that, simply because patients primary cause for admission was other than nonadherence, does not mean those patients were adherent. Also, the difficulty in identifying the cause of decompensation at the time of inclusion should be considered, although strategies have been used to minimize the possibility of bias.

\section{Conclusions}

Patients admitted for decompensated HF exhibited a high degree of knowledge about sodium, and the opinions of family members and health professionals had a positive influence on adherence behaviors. The main barriers to adherence concern palatability and dietary preferences. Patients whose decompensation was caused by nonadherence appeared to be more severely ill and endorsed a greater number of barriers that prevent adequate behavior.

In this population, interventions could be designed to include not only patients but their family members as well, and could concern ways of gradually training the palate to accept lowsalt foods, starting, for instance, with a gradual reduction in industrialized food intake. Other interventions could include teaching participants to prepare meals using no-salt seasonings - many of them natural - that can enhance the flavor, aroma, and even the appearance of food.

Further studies are necessary to help healthcare providers 
to elucidate better educational and counseling strategies for non-pharmacological treatment of these patients. Finally, we expect that, as an instrument validated and reliable for use in Brazil, the DSRQ will be administered in other settings and scenarios.

\section{CONFLicts OF INTEREST Disclosure}

The authors declare that there is no conflict of interest.

\section{REFERENCES}

[1] Go AS, Mozaffarian D, Roger VL, et al. American Heart Association Statistics Committee and Stroke Statistics Subcommittee. Heart disease and stroke statistics-2014 update: a report from the American Heart Association. Circulation. 2014; 129(3): e28-e292. PMid:24352519 https://doi.org/10.1161/01.cir.0000441 139.02102 .80

[2] Bocchi EA. Heart failure in South America. Curr Cardiol Rev. 2013; 9(2): 147-56. PMid:23597301 https://doi.org/10.2174/1573 403X11309020007

[3] Fonarow GC, Abraham WT, Albert NM, et al. Factors identified as precipitating hospital admissions for heart failure and clinical outcomes: findings from OPTIMIZE-HF. Arch Intern Med. 2008; 168: 847-54. PMid:18443260 https://doi.org/10.1001/archinte .168 .8 .847

[4] Gupta D, Georgiopoulou VV, Kalogeropoulos AP, et al. Dietary Sodium Intake in Heart Failure. Circulation. 2012; 126: 479-85. PMid:22825409 https://doi.org/10.1161/CIRCULATIONAHA .111 .062430

[5] Mangini S, Silveira FS, Silva CP, et al. Insuficiência cardíaca descompensada na unidade de emergência de hospital especializado em cardiologia. Arq Bras Cardiol. 2008; 90: 433-40. https : //doi .or g/10.1590/S0066-782X2008000600008

[6] Roger VL. Epidemiology of heart failure. Circ Res. 2013; 113(6): 646-59. PMid:23989710 https://doi.org/10.1161/CIRCRESA HA. 113.300268

[7] Rabelo ER, Aliti GB, Linch GFC, et al. Non-pharmacological management of patients with decompensated heart failure: a multicenter study - EMBRACE - EMBRACE. Acta Paul Enferm. 2012; 25: 6605. https://doi.org/10.1590/S0103-21002012000500003

[8] Ambardekar AV, Fonarow GC, Hernandez AF, et al. Characteristics and in-hospital outcomes for nonadherent patients with heart failure: findings from Get With The Guidelines-Heart Failure (GWTG-HF). Am Heart J. 2009; 158: 644-52. PMid:19781426 https://doi.org/10.1016/j.ahj.2009.07.034

[9] Arcand J, Ivanov J, Sasson A, et al. A high-sodium diet is associated with acute decompensated heart failure in ambulatory heart failure patients: a prospective follow-up study. Am J Clin Nutr. 2011; 93: 332-7. PMid:21084647 https://doi.org/10.3945/ajcn.1 10.000174

[10] Diaz A, Ciocchini C, Esperatti M, et al. Precipitating factors leading to decompensation of chronic heart failure in the elderly patient in South-American community hospital. Am J Geriatr Cardiol. 2011; 8: 12-14. PMid:22783279 https://doi .org/10.3724/SP. J 1263. 2011.00012

[11] Joseph SM, Cedars AM, Ewald GA, et al. Acute Decompensated Heart Failure: contemporary medical management. Texas Heart Inst J. 2009; 36: 510-20. PMid:20069075

[12] Lennie TA, Chung ML, Moser DK. What Should We Tell Patients with Heart Failure about Sodium Restriction and How Should We Counsel Them? Curr Heart Fail Rep. 2013; 10: 2019-26.
PMid:23857162 https://doi.org/10.1007/s11897-013-014 5-9

[13] Nieuwenhuis MMW, Jaarsma T, van Veldhuisen DJ, et al. LongTerm Compliance with Nonpharmacologic Treatment of Patients with Heart Failure. Am J Cardiol. 2012; 110: 392-7. PMid:22516525 https://doi.org/10.1016/j.amjcard.2012.03.039

[14] Saccomann ICRS, Cintra FA, Gallani MCBJ. Fatores associados às crenças sobre adesão ao tratamento não medicamentoso de pacientes com insuficiência cardíaca. Rev Esc Enferm USP. 2014; 48 : 18-24. PMid:24676104 https ://doi .org/10.1590/S0080-623 420140000100002

[15] Rabelo ER, Aliti GB, Goldraich L, et al. Non-Pharmacological Management of Patients Hospitalized with Heart Failure at a Teaching Hospital. Arq Bras Cardiol. 2006; 87: 352-8. PMid:17057937

[16] Bentley B, Lennie TA, Biddle M, et al. Demonstration of psychometric soundness of the Dietary Sodium Restriction Questionnaire in patients whit heart failure. Heart Lung. 2009; 38: 1218. PMid:19254630 https://doi.org/10.1016/j.hrtlng. 200 8.05 .006

[17] Wu J, Moser DK, Lennie TA, et al. Medication Adherence in Patients Who Have Heart Failure: a review of the literature. Nurs Clin N Am. 2008; 43: 133-53. PMid:18249229 https://doi.org/10.1016/ j.cnur.2007.10.006

[18] Carlson KJ, Lee DC, Goroll AH, et al. An analysis of physicians' reasons for prescribing long-term digitalis therapy in outpatients. J Chronic Dis. 1985; 38: 733-9. https://doi.org/10.1016/0021 -9681 (85) 90115-8

[19] Yanci CW, Jessup M, Bozkurt B, et al. 2013 ACCF/AHA guideline for the management of heart failure: a report of the American College of Cardiology Foundation/American Heart Association Task Force on Practice Guidelines. Circulation. 2013; 128: e240-e327. PMid:23741058 https://doi.org/10.1161/CIR.0b013e3182 9 e8776

[20] D'Almeida KSM, Souza GC, Rabelo ER. Cross-cultural adaptation into Brazilian portuguese of the Dietary Sodium Restriction Questionnaire (DSRQ). Arq Bras Cardiol. 2012; 98: 70-5. PMid:22159403 https://doi.org/10.1590/S0066-782X2011005000122

[21] D'Almeida KSM, Souza GC, Rabelo-Silva ER. Validity and reliability of the Dietary Sodium Restriction Questionnaire (DSRQ). Nutr Hosp. 2013; 28: 1702-9. PMid:24160236

[22] Human Experimentation: Code of Ethics of W.M.A. Br Med J. 1964; 2: 177. PMid:14150898 https://doi.org/10.1136/bmj . 2.54 02.177

[23] Dunbar SB, Clark PC, Reilly CM, et al. A Trial of Family Partnership and Education Interventions in Heart Failure. J Card Fail. 2013; 19: 829-41. PMid:24331203 https ://doi .org/10.1016/j.cardfa il.2013.10.007

[24] Taylor RS, Ashton KE, Moxham T, et al. Reduced dietary salt for the prevention of cardiovascular disease: a meta-analysis of randomized controlled trials (Cochrane Review). Am J Hypertens. 2011; 24: 843-53. PMid:21731062 https ://doi.org/10.1038/ajh. 2011 .115

Published by Sciedu Press 
[25] Welsh D, Lennie TA, Marcinek R, et al. Low-sodium diet selfmanagement intervention in heart failure: pilot study results. Eur J Cardiovasc Nurs. 2013; 12: 87-95. PMid:22492785 https : //doi . org/10.1177/1474515111435604

[26] Chung ML, Lennie TA, Mudd-Martin G, et al. Adherence to a lowsodium diet in patients with heart failure is best when family members also follow the diet: a multicenter observational study. J Cardiovasc Nurs. 2015; 30: 44-50. PMid:24165698 https ://doi .org/10.1 097/JCN. 0000000000000089

[27] Bocchi EA, Cruz F, Guimarães G, et al. Long-term prospective, randomized, controlled study using repetitive education at sixmonth intervals and monitoring for adherence in heart failure outpatients: the REMADHE trial. Circ Heart Fail. 2008; 1: 115-24. PMid:19808281 https://doi.org/10.1161/CIRCHEARTFAILU RE.107.744870

[28] Collins S, Storrow AB, Albert NM, et al. Early Management of Patients with Acute Heart Failure: state of the art and future directions. A consensus document from the Society for Academic Emergency Medicine/Heart Failure Society of America Acute Heart Failure Working Group. J Card Fail. 2015; 21: 27-43. PMid:25042620 https://doi.org/10.1016/j.cardfail.2014.07.003

[29] Bentley B, De Jong MJ, Moser DK, et al. Factors related to nonadherence to low sodium diet recommendations in heart failure patients. Eur J Cardiovasc Nurs. 2005; 4: 331-6. PMid:15935733 https://doi.org/10.1016/j.ejcnurse.2005.04.009

[30] Heo S, Lennie TA, Moser DK, et al. Heart failure patients' perceptions on nutrition and dietary adherence. End J Cardiovasc Nurs.
2009; 8: 323-8. PMid:19589729 https://doi.org/10.1016/j. ejcnurse.2009.05.005

[31] de Souza JT, Matsubara LS, Menani JV, et al. Higher salt preference in heart failure patients. Appetite. 2012; 58: 418-23. PMid:22019543 https ://doi .org/10.1016/j. appet. 2011.09.021

[32] Sanders PW. Dietary salt intake, salt sensitivity, and cardiovascular health. Hypertension. 2009; 53: 442-5. PMid:19153264 https : //doi.org/10.1161/HYPERTENSIONAHA.108.120303

[33] Aliti GB, Linhares JC, Linch GF, et al. Signs and symptoms in patients with decompensated heart failure: priorities nursing diagnoses. Rev Gaúch Enferm. 2011; 32: 590-5. https ://doi.org/10.159 0/S1983-14472011000300022

[34] Domingues FB, Clausell N, Aliti GB, et al. Education and Telephone Monitoring by Nurses of Patients with Heart Failure: Randomized Clinical Trial Arq Bras Cardiol. 2011; 96: 233-9. PMid:21308343 https : //doi.org/10.1590/S0066-782X2011005000014

[35] Mussi CM, Ruschel KB, Souza EM, et al. Home visit improves knowledge, self-care and adhesion in heart failure: Randomized Clinical Trial HELEN-I. Rev Latino-Am Enfermagem. 2013; 21: 20-8. https : //doi.org/10.1590/S0104-11692013000700004

[36] de Souza EN, Rohde LE, Ruschel KB, et al. A nurse-based strategy reduces heart failure morbidity in patients admitted for acute decompensated heart failure in Brazil: the HELEN-II clinical trial. Eur J Heart Fail. 2014; 16: 1002-8. PMid:25044072 https : //doi .org/ 10.1002 /ejhf .125 